\title{
Collecting primary materials of major ethnic groups
}

\author{
By Connie V. Dowell \\ Director, External Relations \\ University of Califormia, Santa Barbara
}

\section{The California Ethnic and Multicultural Archives Project.}

A $\mathbf{s}$ archivists we are the keepers of the fine thread that links the past with the future so that future generations will know how they became who they are. That responsibility was never more important than now as we enter the truly multicultural, multi-ethnic future that lies ahead," says March Fong Eu, California's Secretary of State. To help fulfill that responsibility, she co-chairs the advisory board of the California Ethnic and Multicultural Archives (CEMA).

Located in the University of California, Santa Barbara (UCSB) Library, this ambitious project is gathering primary source materials that document the cultural and political experiences of California's major ethnic groups.

"So much of the early documentation of our California heritage was lost forever simply because the importance of the materials was not considered when they were still available," says Eu. "This archives project will help avoid those mistakes by gathering and indexing significant records as they are created and discovered." Co-chairing the advisory board, she says, gives her an opportunity to give CEMA "both her professional and personal support."

Serving with Eu as co-chairs of the board are Lawrence Baca, a senior trial attomey in the U.S. Department of Justice, Speaker Willie Brown of the California State Assembly, and playwright and filmmaker Luis Valdez. The co-chairs represent the ethnic groups that are the focus of the archives: Native American, Asian American, African American, and Chicano/Latino.

\section{Developing the Chicano/Latino collection}

UCSB's relationship with Valdez goes back to 1985 when he decided to donate his papers and the archives of the theater that he founded, $\mathrm{El}$ Teatro Campesino. He is best known as the author of the play Zoot Suit and as director of the movie $L a$ Bamba. El Teatro Campesino, which won an Obie Award for off-Broadway theater in 1968 , is now considered the most influential bilingual Chicano theater in the United States.

"Since 1985 both El Teatro Campesino and I have had a close working relationship with the UCSB Library," says Valdez. "They had won our confidence, they worked out ways to meet our particular needs as a working, active, theatre company, and assured the long-term preservation of valuable cultural materials." A $\$ 136,000$ grant from the Ford Foundation provided funds for preserving and processing the archives of $\mathrm{El}$ Teatro.

Two Library Services and Construction Act (LSCA) grants totaling $\$ 142,221$ from the California State Library support another project that seeks to disseminate CEMA's rich collection to a broader state audience. Proyecto CARIDAD (Chicano Art Resources Information Development and Dissemination) documents the contribution of Chicano artists and provides copies of slides of their works for research and use by libraries, community groups, and schools.

The archives of four major Chicano/Latino cultural arts collectives-Centro Cultural de la Raza (San Diego), Self-Help Graphics and Art (Los 
Angeles), Galeria de la Raza (San Francisco), and the Royal Chicano Air Force (Sacramento) - document this important art movement which began in the mid-1960s. These collections are complemented by the personal collections of artists Jose Montoya, Ralph Maradiaga, Patricia Rodriguez, and Richard Duardo. The two-year project, which began in 1990 , is producing visual arts kits with selected slides and printed resource guides to be placed in public libraries and museums throughout the state.

UCSB assistant professor of art history Ramon Favella has been a strong supporter of the library's efforts to collect Chicano art for university research and for public access. "What's important to keep in mind is that Chicano art was created for all people of all ethnicities and classes to appreciate," he says.

These important Chicano theater and art collections form the basis of a Chicano/Latino archival program which was underway for more than seven years in the UCSB Library and is now a component of CEMA. Organized less than two years ago, CEMA has been expanding from these strengths. "While CEMA has one of the best Chicano/Latino collections in the country, we are only beginning our efforts to secure the important archival collections of other ethnic groups," says Joseph A. Boissé, UCSB's university librarian. "We realize this task is both enormous and extremely important."

\section{Asian American materials acquired as contacts developed}

Boissé said that collection of Asian American materials has increased since contacts have been developed with the Asian American community. "Our advisory board has already proven to be exceedingly helpful in this undertaking. A perfect example of that assistance is the work that California Secretary of State March Fong Eu has done to introduce our project to various groups within the Asian American community. Through her help,
Asian American archives are now included among our collections," says Boissé.

The archives of the Asian American Theater Company of San Francisco, the largest and secondoldest Asian American Theater in North America, is the most recent CEMA acquisition. At the heart of this collection are hundreds of scripts by such notable playwrights as David Henry Hwang, Philip Gotanda, FrankChin, and Genny Lim.

The Chinese American Political Association was CEMA's first archive from that ethnic group. The Oakland group, which was formed in 1984 to advocate social rights and constitutional privileges for Chinese Americans, donated files on voter registration drives, ballot analyses, position papers, photographs, and news clippings. "If Asians hope to change things, they have to unite and get involved politically. We try to show our members that politics is related to their lives," says Edwin Kung, president of the 700-member group.

Working with the files of groups that have daily operating needs sometimes poses challenges for CEMA's new director, Salvador Guerena. "We have tried to work with each group to meet their individual needs," he explains. "Some groups have been surprised that libraries are interested in their day-to-day records. Those who make history are usually too close to the process to know that their desks and files are filled with the grist of history." The archive project collects materials in any format from computer disks to serigraphs, personal correspondence to minutes of meetings.

\section{Faculty members help acquire collections}

UCSB faculty members have also played an important role in locating collections. Associate professor of Black Studies Douglas Daniels recently donated materials on the Bay Area Black Panther Party (San Francisco) collected by Richard 
Aoki, an organizer of the Bay Area Black Panther support movement. This collection includes several early issues of the Black Panther party newspaper published in 1966, flyers from the Huey Newton Defense Committee, and materials from Eldridge Cleaver's U.S. Presidential bid with the Peace and Freedom Party.

"In my research seminar on the black community and the police it will be useful for students to learn how widely reported the Black Panthers were and how influential they were," says Daniels. "The students can also see how the Panthers presented their own case, and compare the view as insiders versus outsiders."

"It's enormously gratifying to see how many scholars are already using these materials in both their teaching and research. These collections directly support the work of the academic departments on campus," says Boissé. "CEMA also helps the university realize its commitment to create and nurture aculturally diverse academic environment."

"One of UCSB's major academic planning goals is to increase diversity within our institution. The Library's CEMA project perfectly complements this goal. I have given CEMA my full support and am pleased to serve on its advisory board," says BarbaraS. Uehling, UCSB chancellor. "The archive's primary resource materials will help students and scholars from all backgrounds better understand the rich heritage and accomplishments of California's ethnic groups."

University librarian Boissé says that research libraries should play a more aggressive role in collecting and preserving useful and important primary resource materials. "The records and personal papers that CEMA is acquiring reflect history from the point of view of the outsider looking/ coming in. Although not ignored, that point of view is all too frequently downplayed in scholarship. CEMA will make it more difficult for future scholars to ignore minority points of view in dealing with the evolution of California during the second half of the 20th century," he says.

George Lipsitz, associate professor of American studies and history at the University of Minnesota, agrees with Boissé. "These collections are rare resources, documenting an extraordinarily significant moment in modern U.S. art and urban history," he says. "Their availability will be an important step in rectifying the historically unbalanced and distorted accounts of American culture that have followed from the unbalanced nature of the collections of primary sources."

Lawrence Baca, CEMA advisory board co-chair, thinks that these collections will provide information that will help people understand themselves as well as others. "In the past, it was cultural conflict, not cultural diversity. Our long history of misunderstanding ethnic groups comes from a lack of knowledge. Access to the kinds of materials that CEMA collects will be important for people from all groups to study to give them a better perspective on themselves as well as others,"says Baca, a Pawnee and the highest ranking Native American at the Justice Department. To make this point, he recalls an old saying: "When two men meet there are really six present —each as he sees the other man, each as he sees himself and each as he truly is."

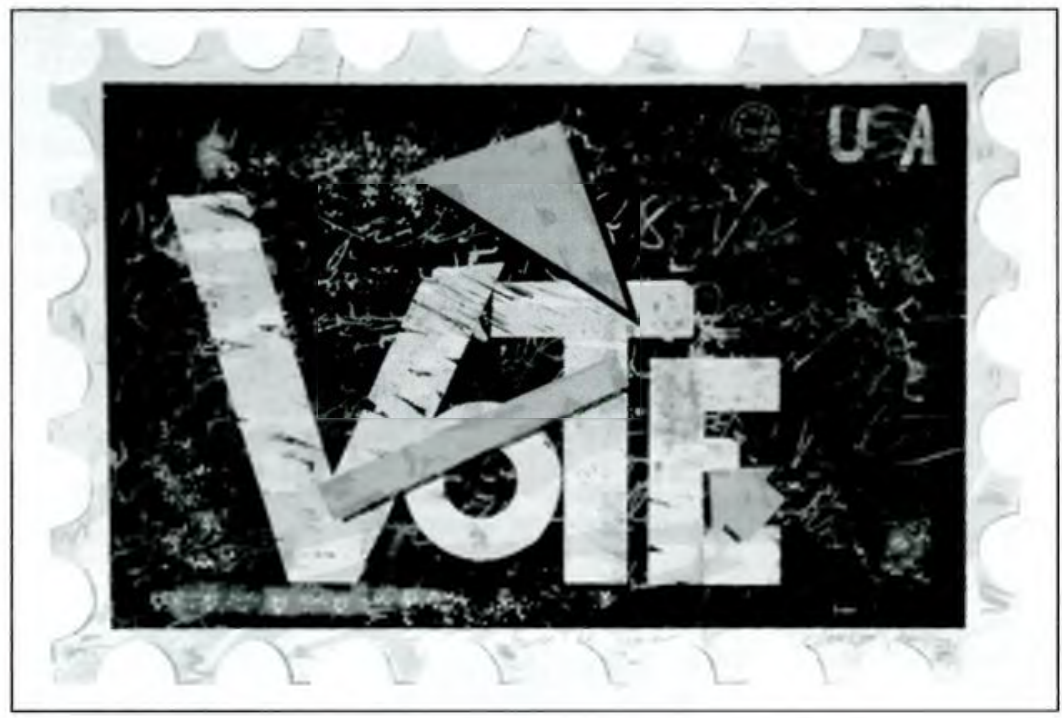

A work titled "Now Is the Time" by Alonso Davis and part of the Self Help Graphics and Art Archive at the University of California, Santa Barbara. 


\section{Cost-effective access to scientific literature in $35=$ fields sing}

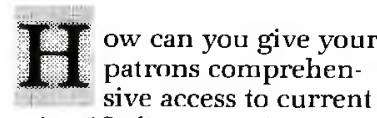
scientific literature in a wide range of fields?

Cambridge Scientific Abstracts journals provide a solution to this dilemma with 35 journals that cover major disciplines in the life sciences, environmental sciences, technology, and management.

By supplementing

Medical and Biological Sciences

$\square$ Biochemistry Abstracts, Part 1: Biological Membranes Monthly

$\square$ Biochemistry Abstracts, Part 2: Nucleic Acids Monthly

$\square$ Biochemistry Abstracts, Part 3: Amino Acids, Peptides \& Proteins Monthly

$\square$ Biotechnology Research Abstracts Bimonthly

$\square$ Calcified Tissue Abstracts Quarterly

$\square$ Chemoreception Abstracts Quarterly

$\square$ Genetics Abstracts Monthly

$\square$ RP Human Genome Abstracts Bimonthly

$\square$ Immunology Abstracts Monthly

$\square$ Microbiology Abstracts, Section A: Industrial o $^{\circ}$ Applied Microbiology Monthly

$\square$ Microbiology Abstracts, Section B: Bacteriology Monthly

$\square$ Microbiology Abstracts, Section C: Algology, Mycology \& Protozoology Monthly

$\square$ Neurosciences Abstracts Monthly

$\square$ PP Oncogenes \&o Growth Factors Abstracts Quarterly

$\square$ Toxicology Abstracts Monthly

$\square$ Virology \& AIDS Abstracts Monthly

RP: Recently Published NE: Newly Expanded
Fisheries, Aquatic Sciences, and Zoology

$\square$ Animal Behavior Abstracts Quarterly

$\square$ Aquatic Sciences \& Fisheries Abstracts (ASFA), Part 1: Biological Sciences \& Living Resources Monthly

$\square$ Aquatic Sciences \& Fisheries Abstracts (ASFA), Part 2: Ocean Technology, Policy \& NonLiving Resources Monthly

$\square$ RP Aquatic Sciences \&

Fisheries Abstracts (ASFA), Part 3: Aquatic Pollution \& Environmental Quality Bimonthly

$\square$ NE ASFA Aquaculture Abstracts Bimonthly

$\square$ RP ASFA Marine

Biotechnology Abstracts Quarterly

$\square$ Entomology Abstracts Monthly $\square$ Oceanic Abstracts Bimonthly

For more information or a sample copy, write or fax today:

$$
\text { (301) 961-6720 }
$$

Attention:Marketing Department

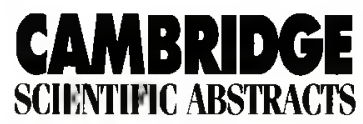

A Division of Cambridge Information Group 7200 Wisconsin Avenue

Bethesda, Maryland 20814-4823 USA your full-text subscriptions, Cambridge journals give you a cost-effective means to cover thousands of publications... so your patrons can keep up with important global research. These journals provide informative abstracts drawn from up to 5,500 worldwide publications, as well as comprehensive indexing to help you find specific information fast.
Pollution and the Entiromment

$\square$ RP ASFA Part 3: Aquatic Pollution \& Environmental Quality Bimonthly

$\square$ Digests of Environmental Impact Statements Bimonthly

$\square$ Ecology Abstracts Monthly $\square$ Pollution Abstracts Bimonthly

Engineering, Computer Science, and Market Research

$\square$ Computer \& Information Systems Abstracts Monthly

$\square$ Conference Papers Index Bimonthly

$\square$ Electronics \& Communications Abstracts Bimonthly

$\square$ RP FINDEX: The Worldwide Directory of Market Research Reports, Studies $\&$ Surveys Semiannual

$\square$ Health $\sigma$ Safety Science Abstracts Quarterly

$\square$ ISMEC: Mechanical Engineering Abstracts Bimonthly

$\square$ RP Risk Abstracts Quarterly

$\square$ Solid State \& Superconductivity Abstracts Quarterly

\section{Magnetic Tape Inabases}

Most of the journals listed here are available on magnetic tape for your Local Area Network. For more information or to obtain a sample tape, please fax or write on your official letterhead. 